\title{
Macrophage Polarization and TCM Intervention
}

\author{
Dan-Dan Zhang1* and Ka Bian ${ }^{1,2,3 *}$ \\ ${ }^{1}$ Shanghai University of Traditional Chinese Medicine, China \\ ${ }^{2}$ Department of Biochemistry and Molecular Medicine, George Washington University, USA \\ ${ }^{3}$ George Washington Cancer Center, Washington, USA
}

Submission: December 05, 2017; Published: December 11, 2017

*Corresponding author: Ka Bian, Shanghai University of Traditional Chinese Medicine, CaiLun road 1200, Shanghai 201203, People’s Republic of China, China, Email: bcmkxb@gwu.edu

Dan-Dan Zhang, Shanghai University of Traditional Chinese Medicine, CaiLun road 1200, Shanghai 201203, People's Republic of China, China, Email: izhangdd@126.com

\section{Abstract}

Macrophages play a critical role in innate immunity. Macrophage polarization initiated by diverse microenvironment mediators leads to different functions. Recent evidences convincingly demonstrate that various events during macrophage polarization are regulated in epigenetic mechanisms. This review showcased the current knowledge on the polarization of macrophage between M1 and M2, may provide potential therapeutic targets to macrophage-related disorders and candidates from TCM that regulate polarization emerged new strategy to treat chronic inflammatory diseases including immune disorder and cancer.

Keywords: Macrophage; Phenotype; Polarization; TCM

\section{Opinion}

Macrophages are solely derived from monocytes and can be generated during embryonic development and adult stages [1].

Macrophages are the critical effect cells of innate immunity and display a broad range of plasticity [2-11]. Under the physiological conditions, quiescent or inactivated macrophages (M0) eat out debris and secret nutritious factors. In the case of external challenges such as infection or injury, macrophages are converted to an M1 phenotype in which they release cytokines, chemokines and reactive oxygen species (ROS), conferring macrophages with host defense to clear pathogens. Macrophages can also alternatively convert to M2 phenotype in which they appear to suppress the pro-inflammatory cascades and promote tissue repair. If these processes are not tightly regulated, chronic inflammation can cause tissue damage and often lead to various pathological conditions [12-14]. Especially, the accumulation of M2-like macrophages is closely associated with metastasis and development of cancers [15].

M1 and M2 phenotypes represent two end points of macrophage polarization statuses [16-19]. In fact, M1, M2 and intermediate polarized sub-populations coexist during disease progression. Upon the exposure to the stimulation from the niche, macrophages can undergo dynamic transition between and M1 and M2 in order to adapt the need of tissue homeostasis $[20,21]$. Once the balance of sub-population is broken, the dominant sub-population will govern the fates of cells and the disease progression. Environmental factors in the pathological conditions have been recognized as key factors regulating macrophage phenotype switch between M1 and M2. For instance, adipose tissue macrophages from obese $\mathrm{C}$-C motif chemokine receptor 2-knockout (Ccr2-KO) mice display M2-like markers including arginase 1 (Arg-1) and IL10. However, high fat diet increases the population of bone marrow-derived macrophage with M1 characteristics [22]. These findings indicate that this metabolic syndrome creates a microenvironment which domesticates macrophages from M2 to M1 status. In case of cancer, tumor-infiltrating macrophages present a classically activated M1 phenotype and exhibit anti-tumor activities at the earliest stage of neoplasia. Along with tumor development, mediators from the tumor microenvironment progressively drive macrophages to tumor-associated macrophages (TAMs) with an M2-like phenotype [23]. Therefore, targeting the molecular mechanisms controlling macrophage polarization and re-education may represent as attractive therapeutic strategies. 
Considering the essential role of macrophages in the progression of diverse diseases, it is not surprising that an increasing attention has been exerted on defining their characteristics during recruitment, activation and polarization to help better clinical diagnosis, prognosis and even therapeutic applications.

Because of the diversity and plasticity of macrophages, the classification of M1 and M2 phenotypes can apparently simplify the complex situations reflecting how milieu signals regulate macrophage phenotypes, functional changes and transcriptional profiles. It has to be noticed that not only the polarized subpopulations but also at single cell level, macrophages can switch one phenotype to the other or coexist at different pathological conditions.

Knowledge on macrophage polarization will undoubtedly provide the benefits to manipulate and control the fate of macrophages under particular pathological conditions. Many natural productions from Traditional Chinese Medicine (TCM) showed their function in regulating polarization, which maybe balance the Yin and Yang of macrophage polarization to decide the fate of cell in diseases progress, thus provide the abundant source for us to develop the drugs for inflammation, immune and cancer [24-26] (Figure 1).

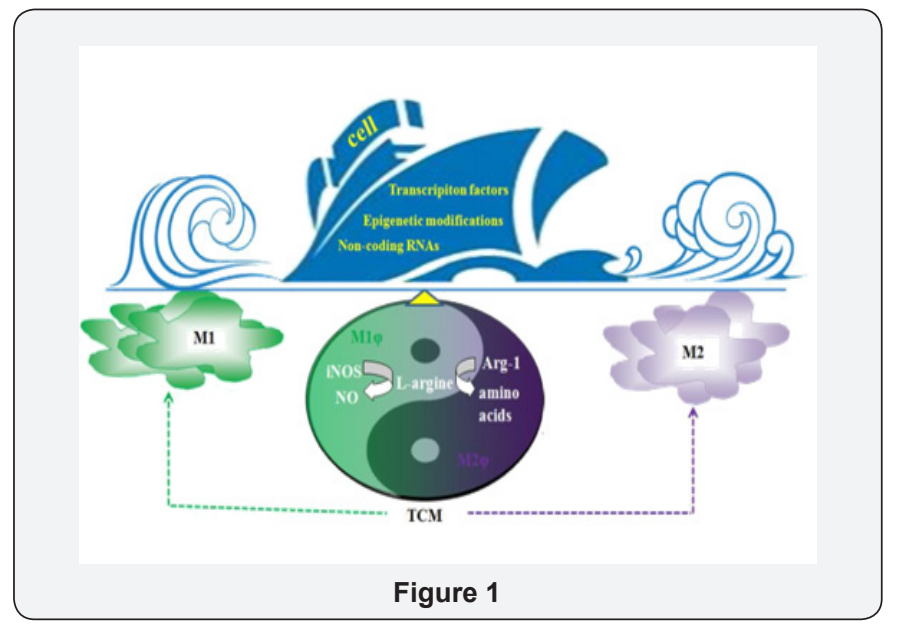

Notes

Author declares no competing financial interest.

\section{Acknowledgment}

This work was supported by Funds of the National Natural Science Foundation of China (81773946,81573673,81001666); Innovation Program of Shanghai MunicipalEducation Commission (13YZ048) ; The Young Scientists Fund of shanghai municipal commission of health and family planning (20144Y0143) and the Foundation of Shanghai Education commission for Outstanding Young Teachers in University (SZY07029).

\section{References}

1. S Epelman, KJ Lavine, GJ Randolph (2014) Origin and functions of tissue macrophages. Immunity 41(1): 21-35.
2. VH Perry, J Teeling (2013) Microglia and macrophages of the central nervous system: the contribution of microglia priming and systemic inflammation to chronic neurodegeneration. Sem Immunopathol 35(5): 601-612.

3. L Zhang, S Zhang, J Yao, Frank J Lowery, Qingling Zhang, et al. (2015) Microenvironment-induced PTEN loss by exosomal microRNA primes brain metastasis outgrowth. Nature 527(7576): 100-104.

4. JM den Haan, G (2012) Kraal Innate immune functions of macrophages subpopulations in the spleen. Journal of Innate Immunity 4(5-6): 437445 .

5. Carey B, Trapnell BC (2010) The molecular basis of pulmonary alveolar proteinosis. Clin Immunol 135(2): 223-235.

6. Wynn TA, Vannella KM (2016) Macrophages in tissue repair, regeneration, and fibrosis. Immunity 44(3): 450-462.

7. ML Novak, TJ Koh (2013) Phenotypic transitions of macrophages orchestrate tissue repair," The American journal of pathology 183(5): 1352-1363.

8. Kleyer A, Schett G (2014) Arthritis and bone loss: a hen and egg story. Curr Opin Rheumatol 26(1): 80-84.

9. Loddo I, Romano C (2015) Inflammatory Bowel Disease: Genetics, Epigenetics, and Pathogenesis. Front Immunol 2(6): 551.

10. GJ Randolph (2014) Mechanisms that regulate macrophage burden in atherosclerosis. Circ Res 114(11): 1757-1171.

11. Varol C, Mildner A, Jung S (2015) Macrophages: development and tissue specialization. Annual review of immunology. Annu Rev Immunol 33: 643-675.

12. Murray PJ, Allen JE, Biswas SK, Fisher EA, Gilroy DW et al. (2014) Macrophage activation and polarization: nomenclature and experimental guidelines. Immunity 41(1): 14-20.

13. Italiani P, Boraschi D (2014) From Monocytes to M1/M2 Macrophages: Phenotypical vs. Functional Differentiation. Front Immunol 5: 514.

14. Sica A, Mantovani A (2012) Macrophage plasticity and polarization: in vivo veritas. J Clin Invest 122(3): 787-795.

15. Alberto M, Paola A, Antonio S, Frances B (2008) Cancer-related inflammation. Nature 454(7203): 436-444.

16. McWhorter FY, Wang T, Nguyen P, Chung T, Liu WF (2013) Modulation of macrophage phenotype by cell shape. Proceedings of the National Academy of Sciences of the United States of America 110(43): 1725317258.

17. Piccinini AM, Midwood KS (2012) Endogenous control of immunity against infection: tenascin-C regulates TLR4-mediated inflammation via microRNA-155. Cell Reports 2(4): 914-926.

18. Huang Z, Luo Q, Yao F, Qing C, Ye J, et al. (2016) Identification of Differentially Expressed Long Non-coding RNAs in Polarized Macrophages. Scientific Reports doi:10.1038/srep19705.

19. Graff JW, Dickson AM, Clay G, McCaffrey AP, Wilson ME (2012) Identifying functional microRNAs in macrophages with polarized phenotypes. J Biol Chem 287(26): 21816-21825.

20. Xue J, Schmidt SV, Sander J, Draffehn A, Krebs W, et al. (2014) Transcriptome-based network analysis reveals a spectrum model of human macrophage activation. Immunity 40(2): 274-288.

21. Lawrence T, Natoli G (2011) Transcriptional regulation of macrophage polarization: enabling diversity with identity. Nature reviews: Immunology 11(11): 750-761.

22. Amano SU, Cohen JL, Vangala P, Tencerova M, Nicoloro SM, et al. (2014) Local proliferation of macrophages contributes to obesity-associated adipose tissue inflammation. Cell Metabolism 19(1): 162-171. 
23. Gordon S, Martinez FO (2010) Alternative activation of macrophages: mechanism and functions. Immunity 32(5): 593-604.

24. Dan-Dan Z, Hong Z, Yuan-Zhi L, Wu R, Xu JW, et al. (2015) AntiInflammatory Effect of 1,3,5,7-Tetrahydroxy-8-isoprenylxanthone Isolated from Twigs of Garcinia esculenta on Stimulated Macrophage. Mediators of Inflammation 2015(2015), p. 11.
25. Chen C, Zhang DD (2014) Anti-Inflammatory Effects of 81 Chinese Herb Extracts and Their Correlation with the Characteristics of Traditional Chinese Medicine. Evidence Based Complement Alternation Medicine 2014(2014), p. 8

26. Xi T, Yuan-Lai W, Xiao-Lu Y, et al. Zhang DD (2014) Ethyl acetate extract of Artemisia anomala S. Moore displays potent anti-inflammatory effect. Evid Based Complement Alternat Med 2014, (2014), p. 10.

\section{Your next submission with Juniper Publishers will reach you the below assets}

- Quality Editorial service

- Swift Peer Review

- Reprints availability

- E-prints Service

- Manuscript Podcast for convenient understanding

- Global attainment for your research

- Manuscript accessibility in different formats

( Pdf, E-pub, Full Text, Audio)

- Unceasing customer service

Track the below URL for one-step submission https://juniperpublishers.com/online-submission.php 